\title{
Silencing protease-activated receptor 2 alleviates ox-LDL-induced lipid accumulation, inflammation, and apoptosis via activation of Wnt/ $\beta$-catenin signaling
}

\author{
Yongsheng Liu ${ }^{1}$, Mei Wei ${ }^{1}$, Gang Liu ${ }^{1}$, Chunmei Song ${ }^{2}$, Man Yang ${ }^{1}$, Zelong Cao ${ }^{1}$ \\ and Mingqi Zheng ${ }^{1}$ \\ ${ }^{1}$ Heart Center, The First Hospital of Hebei Medical University, Shijiazhuang, Hebei, China \\ ${ }^{2}$ CCU2 Department, The First Hospital of Qinhuangdao, Qinhuangdao, Hebei, China
}

\begin{abstract}
Macrophages conversion to foam cells strongly promoted atherosclerosis progression by plaque formation and plaque rupture. Macrophages swallow oxidized-low density lipoprotein (ox-LDL) to promote foam cell formation. Protease-activated receptor 2 (PAR2) has been reported to take part in atherosclerotic development. However, the effects of PAR2 in macrophages were rarely investigated. In this study, human monocyte, THP-1 was induced to macrophages by using phorbol 12-myristate 13-acetate (PMA). Subsequently, an in vitro model was arranged by using oxLDL to treat the macrophages. The data showed that inhibition of PAR2 reduced ox-LDL-induced foam cell formation, inflammation, and apoptosis. Additionally, ox-LDL increased PAR2 and inhibited Dickkopf-related protein 1 (DKK1) expression, which is a Wnt signaling inhibitor. PAR2 knocked-down decreased DKK1 and enhanced expression of Wnt3a, $\beta$-catenin. Meanwhile, DKK1 overexpression reversed the effects of PAR2 on foam cell formation, inflammation, and apoptosis. In summary, PAR2 is essential for the formation of foam cells, inflammation, and apoptosis in macrophages which plays a critical role during atherosclerosis. PAR2 plays roles in macrophages treated with ox-LDL via DKK1/Wnt/ $\beta$-catenin signaling.
\end{abstract}

Key words: Atherosclerosis - Foam cells - Inflammation - Apoptosis - Protease-activated receptor 2

\section{Introduction}

Atherosclerosis occurs in arteries with plaque accumulation. It mainly leads to stroke, heart attack or even death. Plaque is formed by fat, cholesterol, calcium and other substances in the blood. The stages of atherosclerosis including intimal thickening, plaque progression and plaque rupture, which is resulted by immune cell infiltration. Furthermore, it is initiated by the formation of foam cells induced by which macrophages engulf low-density lipoprotein cholesterol (LDL) (Tabas et al. 2007). The foam cell's apoptosis and inflammation accelerate atherosclerosis progression (Wang

Correspondence to: Mingqi Zheng, Heart Center, The First Hospital of Hebei Medical University, No. 89 Donggang Road, Shijiazhuang, Hebei, 050031, China

E-mail: mingqizhenghb@163.com et al. 2018). In the advancement of atherosclerotic plaques, free cholesterol in foam cells is accumulated to result in endoplasmic reticulum stress, which triggers inflammatory responses and subsequently foam cells apoptosis (Zhou et al. 2005; Cai et al. 2015).

Protease-activated receptors (PAR) mediate cell activation by binding serine proteases which are key activators in the coagulation cascade (Antoniak and Mackman 2014). PAR family (PAR1-4) is expressed omnipresently in vascular cells and is associated with atherosclerosis. PAR1 inhibits cholesterol efflux and promotes atherogenesis (Raghavan et al. 2018). Thrombin-induced platelet activation, which could induce platelet-dependent atherosclerosis, is failing in PAR4 deficient mice (Hamilton et al. 2009). PAR1, PAR3 and PAR 4 can be activated by thrombin crucial in hemostasis and thrombosis (Popovic et al. 2010). PAR2 is stimulated by serine proteases including trypsin, tryptase and factor 
$\mathrm{Xa}(\mathrm{FXa})$ except by thrombin. Our previous investigation showed that PAR2 expression was upregulated in patients with atherosclerosis. PAR2 deficiency in mice attenuated atherosclerosis by reducing macrophage accumulation and collagen deposition (Jones et al. 2018). PAR2 activates M1like polarization with a significant increase of IL- $1 \beta$, IL- 6 , and MCP-1 (Chen et al. 2019). Research demonstrates that FXa activates PAR2 to increase inflammation and lipid uptake (Hara et al. 2018), which is essential for plaque formation and further atherosclerosis.

Oxidized-LDL (ox-LDL) is generated during atherogenesis and is essential for the formation of foam cells (Steinberg 1997). In human nonalcoholic fatty liver disease, it has been found that PAR2 controls cholesterol homeostasis and lipid metabolism (Rana et al. 2019). Therefore, we hypothesized that PAR2 participated in the foam cell formation by regulating the ox-LDL uptake. Furthermore, we evaluated the effects of PAR2 in cell apoptosis and inflammation in macrophages stimulated with ox-LDL.

\section{Materials and Methods}

\section{Cell culture}

Human THP-1 cells were purchased from the Cell Culture Center of the Chinese Academy of Medical Sciences (Beijing, China). Cells were incubated in Dulbecco's Modified Eagle Medium (DMEM; Gibco, Thermo Fisher Scientific, USA) with $10 \%$ fetal bovine serum (FBS; Gibco, Thermo Fisher Scientific). THP-1 cells were differentiated with $50 \mathrm{nM}$ phorbol 12-myristate 13 -acetate (PMA) for $48 \mathrm{~h}$ to macrophage. The differentiated cells were used for the following experiments. Cells (75\% confluence) were transfected with siRNA-PAR2-1, siRNA-PAR2-2 or control siRNA (siRNA-NC) which were synthesized by Gene Pharma (Shanghai, China) according to the previous investigation (Yeong et al. 2010). The silence sequence is: sense, 5'-CAUCCACAGAAAAGACUGUTT, and anti-sense, 5'-ACAGUCUUUUCUGUGGAUGTT. The pcDNA3.0-Flag-DKK1 and empty pcDNA3.0 plasmid (Gene Pharma, Shanghai, China) were co-transfected with siRNAPAR2 into cells. Macrophages transfected with PAR2 cloned into pcDNA3.1 (pc-DNA3.1-PAR2) and empty pcDNA3.1 plasmid (Gene Pharma, Shanghai, China). Lipofectamine 2000 (Thermo Fisher Sciences, USA) was used for cell transfection.

\section{CCK-8 detection}

Different doses of ox-LDL with 25, 50, 100 and $150 \mu \mathrm{g} / \mathrm{ml}$ were used to treat THP-1 cells for $24 \mathrm{~h}$. Cell viability was estimated using CCK-8 counting kit-8 (MedChemExpress, Shanghai, China). Treated cells were incubated with CCK-8 reagent for $3 \mathrm{~h}$ at $37^{\circ} \mathrm{C}$. The absorbance was detected at a wavelength of $450 \mathrm{~nm}$. Triplicate measurements were repeated.

\section{Western blotting}

Macrophages were treated with ox-LDL at a concentration of $25,50,100$ and $150 \mu \mathrm{g} / \mathrm{ml}$ for $24 \mathrm{~h}$. In next experiments, macrophages were transfected with shRNA-NC, shRNA-PAR2-1 or shRNA-PAR2-2 for $48 \mathrm{~h}$. Further, macrophages were transfected with shRNA-NC, shRNA-PAR2- 1 for $48 \mathrm{~h}$ and treated with ox-LDL $(100 \mu \mathrm{g} / \mathrm{ml})$ for another $24 \mathrm{~h}$, or macrophages were co-transfected with shRNA-PAR2 and pcDNA3.0-DKK1 for $48 \mathrm{~h}$ and treated with ox-LDL $(100 \mu \mathrm{g} / \mathrm{ml})$ for another $24 \mathrm{~h}$. Other macrophages were treated with ox-LDL $(100 \mu \mathrm{g} / \mathrm{ml})$ or transfected with pcDNA3.1-PAR2 or pcDNA3.1 empty plasmid for $48 \mathrm{~h}$. Proteins were obtained from treated THP-1 cells by using RIPA lysis buffer (Thermo Fisher Scientific, USA). Gel electrophoresis was performed to separate proteins. An equal amount of proteins $(30 \mu \mathrm{g})$ was loaded into the wells of SDS-PAGE (10\%) and transferred to PVDF membranes. The membranes were subsequently treated as previously described (Zahid et al. 2019). The primary antibodies were used as follows: PAR2, NLRP3, ASC, caspase-1, Bid, Bcl-2, cleaved-caspase3, caspase-3, cleaved-caspase9, caspase-9, Wnt3a, GSK3 $\beta$, $\beta$-catenin, and DKK1 (Cell Signaling Technology, USA). The secondary HRP-conjugated anti-rabbit antibody (Cell Signaling Technology, USA) was used in this investigation.

\section{$R T-q P C R$}

Macrophages were treated with ox-LDL at a concentration of $25,50,100$ and $150 \mu \mathrm{g} / \mathrm{ml}$ for $24 \mathrm{~h}$. In next experiments, macrophages were transfected with shRNA-NC, shRNA-PAR2-1 or shRNA-PAR2-2 for $48 \mathrm{~h}$. Further, macrophages co-transfected with shRNA-PAR2 and pcDNA3.0-DKK1 for $48 \mathrm{~h}$. Other macrophages were transfected with pcDNA3.1-PAR2 or pcDNA3.1 empty plasmid for $48 \mathrm{~h}$. RNA was extracted by TRIzol reagent (Thermo Fisher Scientific, USA) in treated cells. The RNA was quantified using NanoDrop ND-2000 (Thermo Fisher Scientific). The relative mRNA expression was determined by real-time PCR using SYBR-Green Real-time PCR Master Mix (Thermo Fisher Scientific). GAPDH was performed as an internal standard. Primers used in this experiment were shown in Table 1. The PCR reaction conditions were as follows: $95^{\circ} \mathrm{C}$ $10 \mathrm{~min}$ for $1 \mathrm{cycle} ; 95^{\circ} \mathrm{C} 15 \mathrm{~s}, 60^{\circ} \mathrm{C} 30 \mathrm{~s}$, and $72^{\circ} \mathrm{C} 30 \mathrm{~s}$, for 40 cycles; $95^{\circ} \mathrm{C} 15 \mathrm{~s}, 60^{\circ} \mathrm{C} 60 \mathrm{~s}, 95^{\circ} \mathrm{C} 15 \mathrm{~s}, 60^{\circ} \mathrm{C} 15 \mathrm{~s}$.

\section{Oil Red O staining}

Macrophages were transfected with shRNA-NC, shRNAPAR2-1 for $48 \mathrm{~h}$ and treated with ox-LDL $(100 \mu \mathrm{g} / \mathrm{ml})$ for 
Table 1. Primers for $\mathrm{qRT}$-PCR of PAR2

\begin{tabular}{lll}
\hline Gene & Sense & Anti-sense \\
\hline PAR2 (NM_005242) & GGGTTTGCCAAGTAACGGC & GGGAACCAGATGACAGAGAGG \\
DKK1 (NM_012242) & AGTGTGTACCAAGCATAGGAGAAAA & TTAGTGTCTCTGACAAGTGTGAAGC \\
GAPDH (NM_014364) & CAATGACCCCTTCATTGACC & TTGATTTTGGAGGGATCTCG \\
\hline
\end{tabular}

another $24 \mathrm{~h}$. Further, macrophages co-transfected with shRNA-PAR2 and pcDNA3.0-DKK1 for $48 \mathrm{~h}$ and treated with ox-LDL $(100 \mu \mathrm{g} / \mathrm{ml})$ for another $24 \mathrm{~h}$. The cell culture medium was removed and washed with PBS three times. Cells were fixed with $4 \%$ paraformaldehyde for $15 \mathrm{~min}$. Cells were subsequently stained with Oil Red O dissolved in isopropanol and water (3:2) for $20 \mathrm{~min}$. Red-stained lipid droplets in cells were observed by an inverted microscope (Olympus, Japan). Finally, the stained cells were exacted by invert microscopy with $\times 400$ magnification.

\section{Measurement of total cholesterol and free cholesterol}

Macrophages were transfected with shRNA-NC, shRNAPAR2-1 for $48 \mathrm{~h}$ and treated with ox-LDL $(100 \mu \mathrm{g} / \mathrm{ml})$ for another $24 \mathrm{~h}$. Further, macrophages co-transfected with shRNA-PAR2 and pcDNA3.0-DKK1 for $48 \mathrm{~h}$ and treated with ox-LDL $(100 \mu \mathrm{g} / \mathrm{ml})$ for another $24 \mathrm{~h}$. The total cholesterol and free cholesterol levels were detected using the commercial kit (E1015, E1016; Applygen Technologies Inc.,
Beijing, China) following the instructions. Cells were treated with lysis buffer for $10 \mathrm{~min}$ and centrifuged at $1500 \times g$ for $10 \mathrm{~min}$. The supernatant was collected and detected at $550 \mathrm{~nm}$.

Levels of TNF- $\alpha, I L-1 \beta, I L-6$, and MCP-1 by ELISA kit

Macrophages were transfected with shRNA-NC, shRNAPAR2-1 for $48 \mathrm{~h}$ and treated with ox-LDL $(100 \mu \mathrm{g} / \mathrm{ml})$ for another $24 \mathrm{~h}$. Further, macrophages co-transfected with shRNA-PAR2 and pcDNA3.0-DKK1 for $48 \mathrm{~h}$ and treated with ox-LDL $(100 \mu \mathrm{g} / \mathrm{ml})$ for another $24 \mathrm{~h}$. Other macrophages treated with ox-LDL $(100 \mu \mathrm{g} / \mathrm{ml})$ or transfected with pcDNA3.1-PAR2 or pcDNA3.1 empty plasmid for $48 \mathrm{~h}$. After stimulation, the culture medium was collected and centrifuged at $1000 \times g$ for $15 \mathrm{~min}$. The levels of tumor necrosis factor-alpha (TNF- $\alpha$ ), interleukin (IL)-1 $\beta$, IL-6 and monocyte chemoattractant protein-1 (MCP-1) in cell supernatant were assessed by commercial kits (all from Abcam, USA).
A

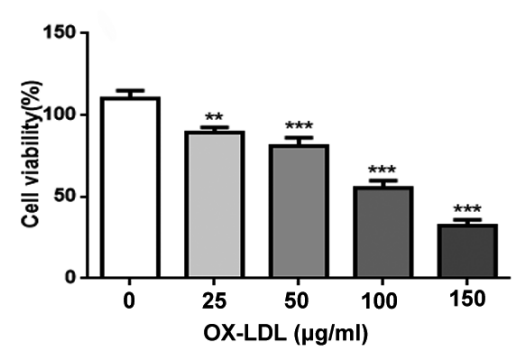

C

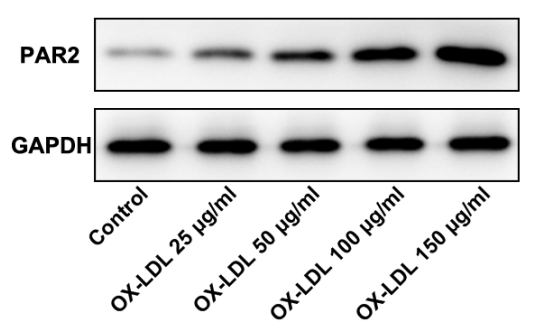

B
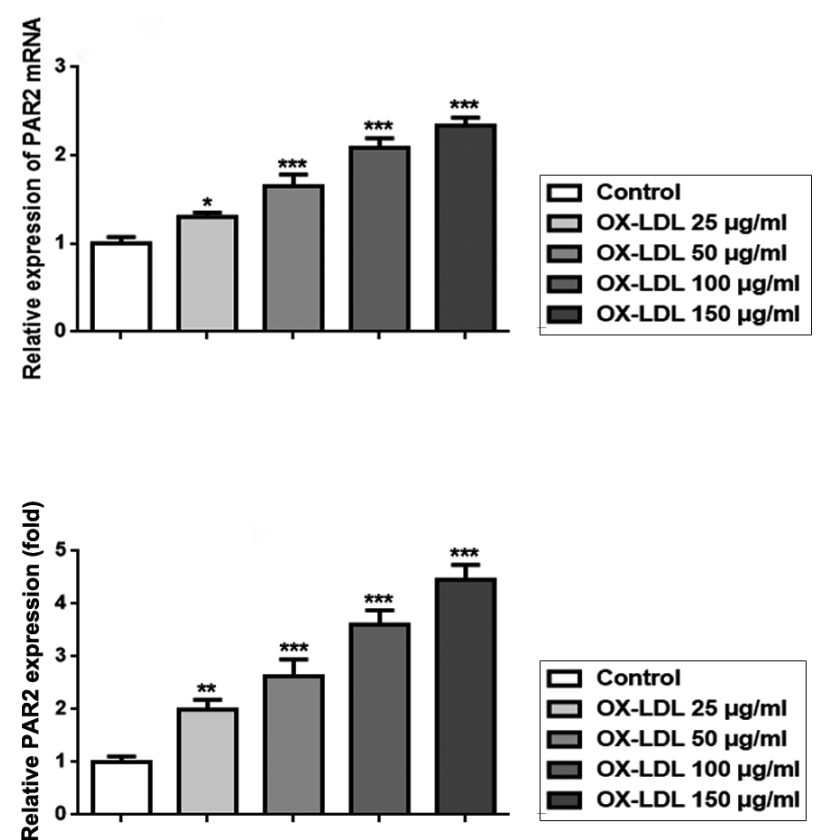

Figure 1. PAR2 expression in ox-LDL-induced THP-1 cells. A. The cell viability in macrophages incubated with different doses of oxLDL as indicated. The mRNA (B) and protein (C) expression of PAR2 in macrophages treated with different concentrations of ox-LDL. ${ }^{\star} p<0.05,{ }^{* *} p<0.01,{ }^{* * *} p<0.001 v$ s. Control group. 


\section{Cell apoptosis analysis}

Macrophages were transfected with shRNA-NC, shRNAPAR2-1 for $48 \mathrm{~h}$ and treated with ox-LDL $(100 \mu \mathrm{g} / \mathrm{ml})$ for another $24 \mathrm{~h}$. Or macrophages were co-transfected with shRNA-PAR2 and pcDNA3.0-DKK1 for $48 \mathrm{~h}$ and treated with ox-LDL for another $24 \mathrm{~h}$. Or macrophages treated with ox-LDL $(100 \mu \mathrm{g} / \mathrm{ml})$ or transfected with pcDNA3.1-PAR2
A

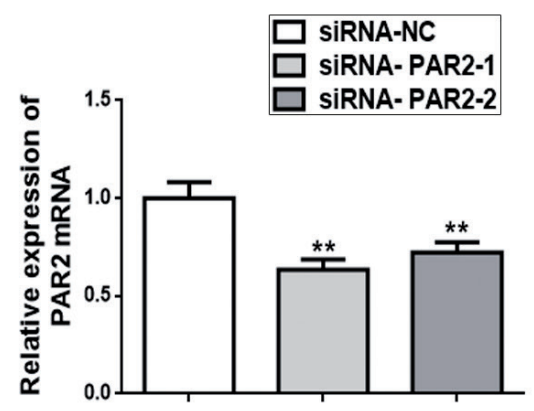

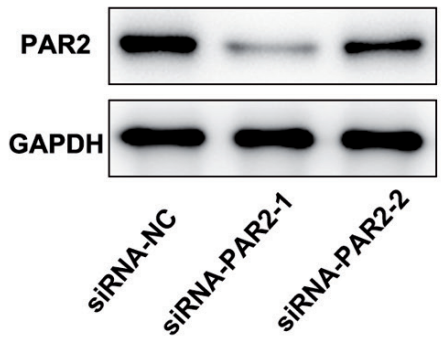

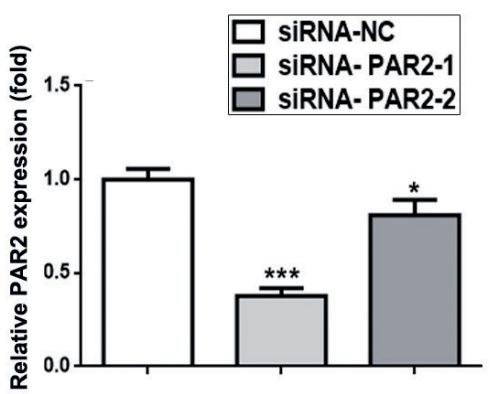

C
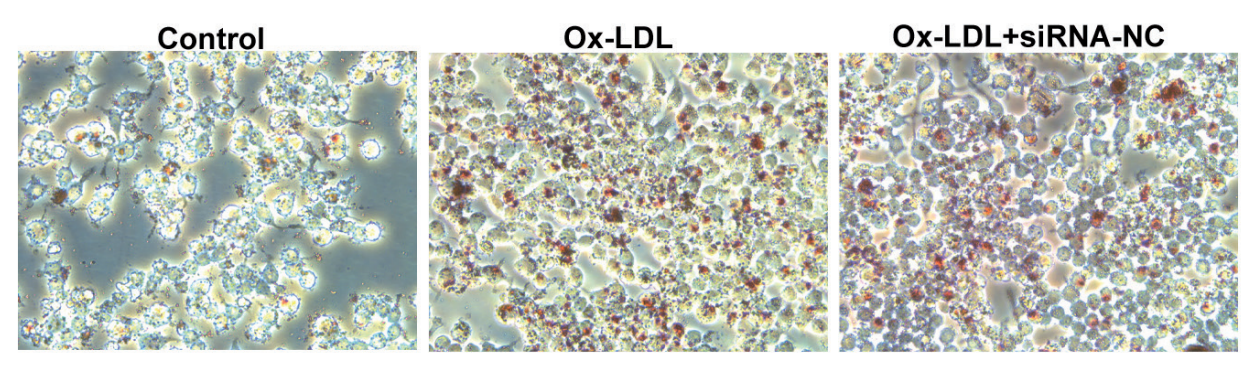

Ox-LDL+SIRNA-NC

OX-LDL+sIRNA-PAR2

D

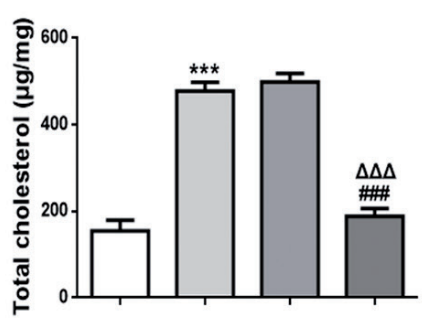

E
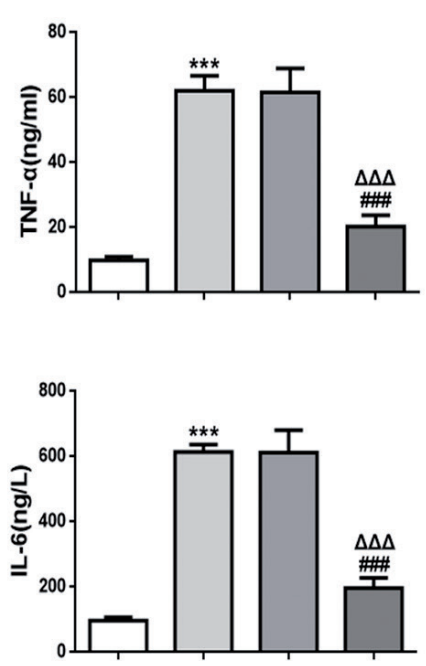
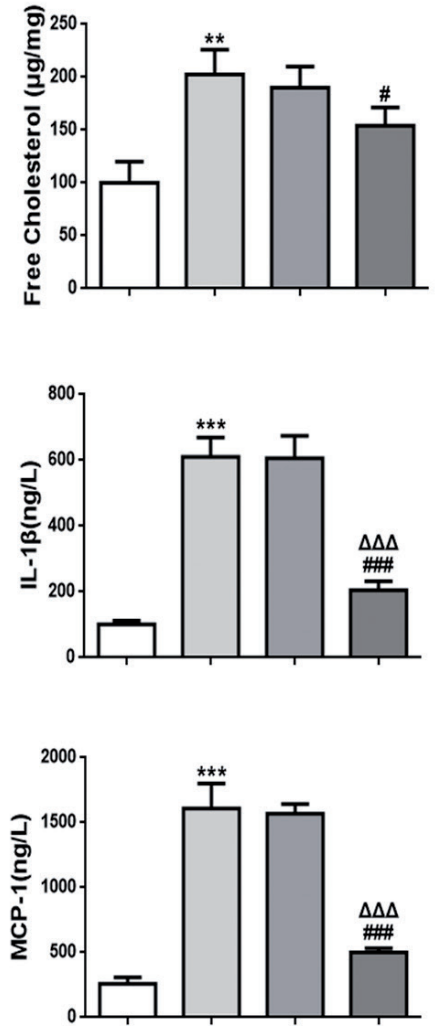

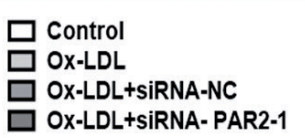

Figure 2. Effects of PAR2 in ox-LDL-induced macrophages. RT-qPCR (A) and Western blotting $(\mathrm{B})$ were performed to detect transfected efficacy of shRNA-PAR2 in macrophages. ${ }^{*} p<$ $0.05,{ }^{* *} p<0.01,{ }^{* *} p<0.001$ vs. siRNA-NC group. C. Representative pictures of Oil Red $\mathrm{O}$ staining were exhibited in different groups (magnification 400x). D. The levels of total cholesterol and free cholesterol in macrophages treated with ox-LDL were detected by the commercial assay kit. E. The inflammatory mediators, TNF- $\alpha$, IL- $1 \beta$, IL- 6 and MCP-1, were detected by the ELISA kit. ${ }^{*} p<0.01$, $* * * p<0.001$ vs. Control group; ${ }^{*} p<0.05$, \#\#\# $p<0.001$ vs. ox-LDL group; ${ }^{\Delta \Delta \Delta} p<0.001$ vs. ox-LDL+siRNA-NC group. 
or pcDNA3.1 empty plasmid for $48 \mathrm{~h}$. Cells were counted with $1 \times 10^{6}$ cells $/ \mathrm{ml}$ and resuspended in $1 \times$ Binding Buffer. Cell apoptosis was measured by PE Annexin V Apoptosis Detection Kit I (BD Pharmigen) using manual instructions. FlowJo software was performed to analyze apoptotic data.

\section{Statistical analysis}

Student's $t$-test and One-way ANOVA followed with Turkey's test in GraphPad 6.0 were performed to analyze the statistical differences. A value $p<0.05$ was shown as significant difference.

\section{Results}

PAR2 knockdown hindered the formation of foam cells, cholesterol accumulation, and inflammation

According to CCK-8 data, ox-LDL dramatically induced cell death as the concentration increasing (Fig. 1A). The mRNA and protein expression of PAR2 was increased by the treatment of ox-LDL with various doses (Fig. $1 B$ and C). $100 \mu \mathrm{g} / \mathrm{ml} \mathrm{ox}$ LDL was performed to do the following experiment.

To determine the role of PAR2, it is knocked-down in THP-1 cells. Both mRNA and protein levels were downregulated (Fig. 2A and B). siRNA-PAR2-1 was used in the following analysis. Figure $2 \mathrm{C}$ showed that ox-LDL treatment dramatically induced lipid accumulation and PAR2 inhibi- tion reversed the effects of ox-LDL. This revealed that PAR2 may participate in the formation of foam cells. Subsequently, total cholesterol and free cholesterol levels were increased significantly in macrophages stimulated with ox-LDL, but PAR2 knocked-down inhibited the expression (Fig. 2D). Besides, ox-LDL dramatically induced the expression of proinflammatory cytokines including TNF- $\alpha$, IL-1 $\beta$, IL- 6 , and MCP-1, and inhibition of PAR2 reduced the expression (Fig. $2 \mathrm{E})$. Also, the inflammasome concluding NOD-like receptor 3 (NLRP3), the apoptosis-associated speck-like protein containing CARD (ASC) and caspase- 1 was activated by ox-LDL and reversed by PAR2 inhibition (Fig. 3). These data indicate that PAR2 is essential for regulating macrophages conversion to foam cell and inflammation activating.

\section{Downregulation of PAR2 suppressed ox-LDL-induced apoptosis}

Due to foam cell apoptosis is further induced lipid stack in the blood vessel, we supposed that PAR2 may affect the apoptosis. Data elucidated that ox-LDL dramatically induced apoptosis in macrophages while PAR2 silence reduced apoptosis (Fig. 4A). Later, protein expression data further confirmed the effects of PAR2 that anti-apoptotic Bcl-2 was dramatically increased after inhibition of PAR2 in macrophages stimulated with ox-LDL (Fig. 4B). The proapoptotic Bid, cleaved-casepase 3 , and cleaved-caspase 9 were decreased by inhibition of PAR2 in macrophages stimulated with ox-LDL (Fig. 4B).
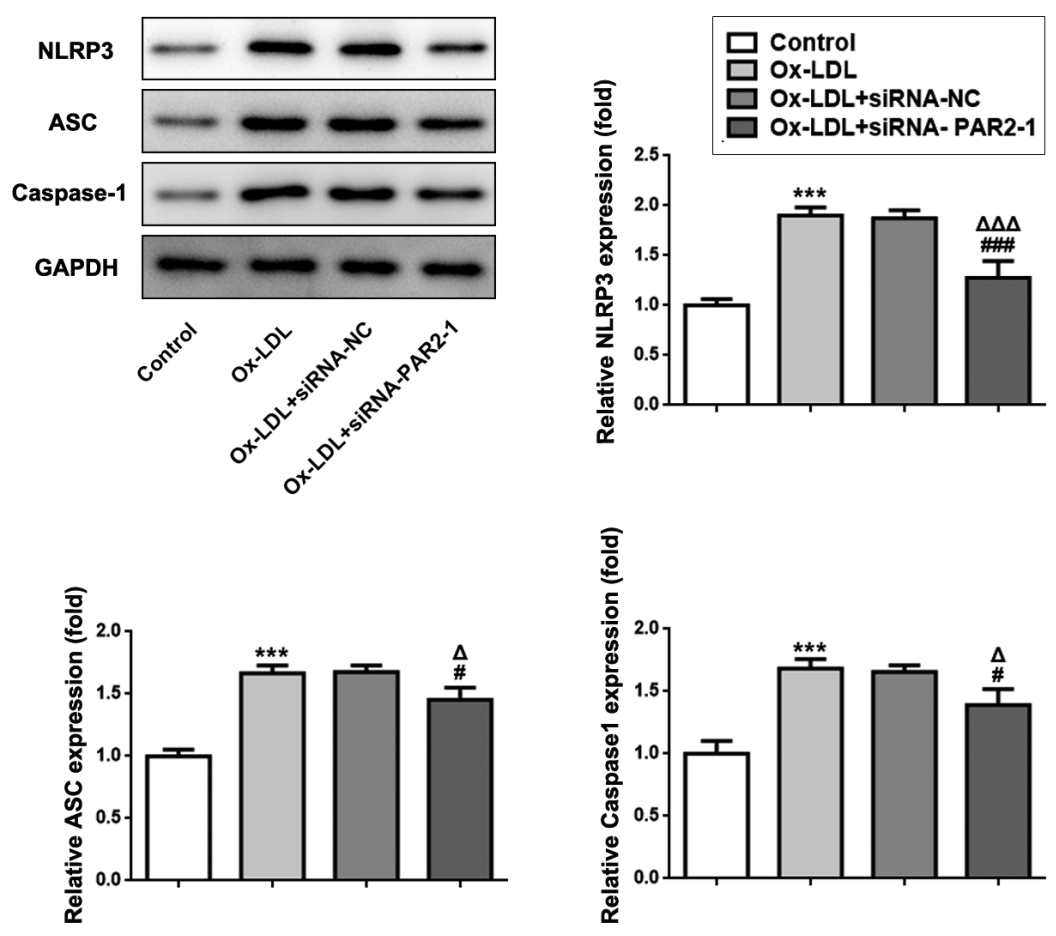

Figure 3. The inflammasome expression in macrophages treated with ox-LDL. Western blotting and protein bands analysis were performed for the determination of the expression of inflammasome complex NLRP3/ASC/caspase- $1 .{ }^{* * *} p<$ 0.001 vs. Control group; ${ }^{\#} p<0.05,{ }^{\# \# \#} p<0.001$ vs. ox-LDL group; ${ }^{\Delta} p<0.05,{ }^{\Delta \Delta \Delta} p<0.001 v s$. ox-LDL+siRNA-NC group. 

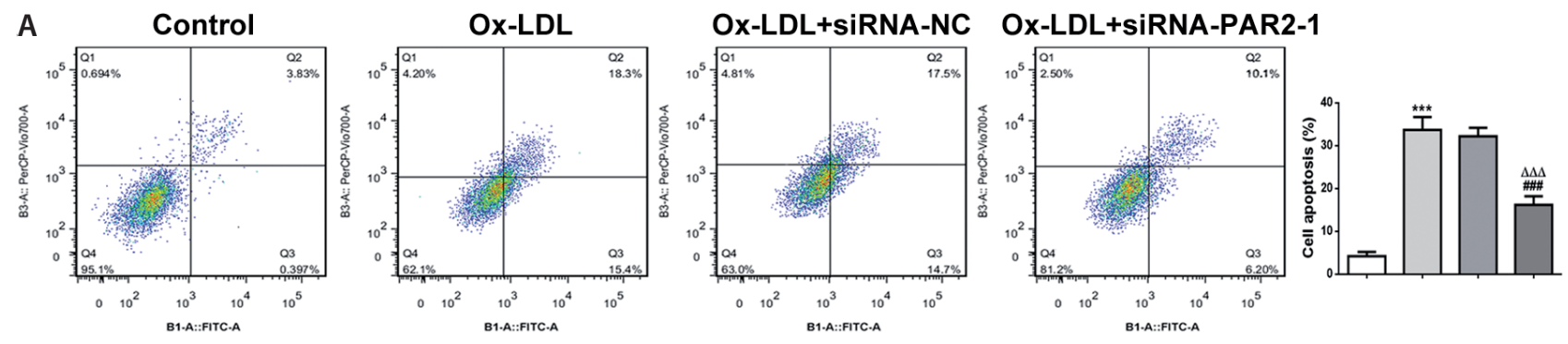

B
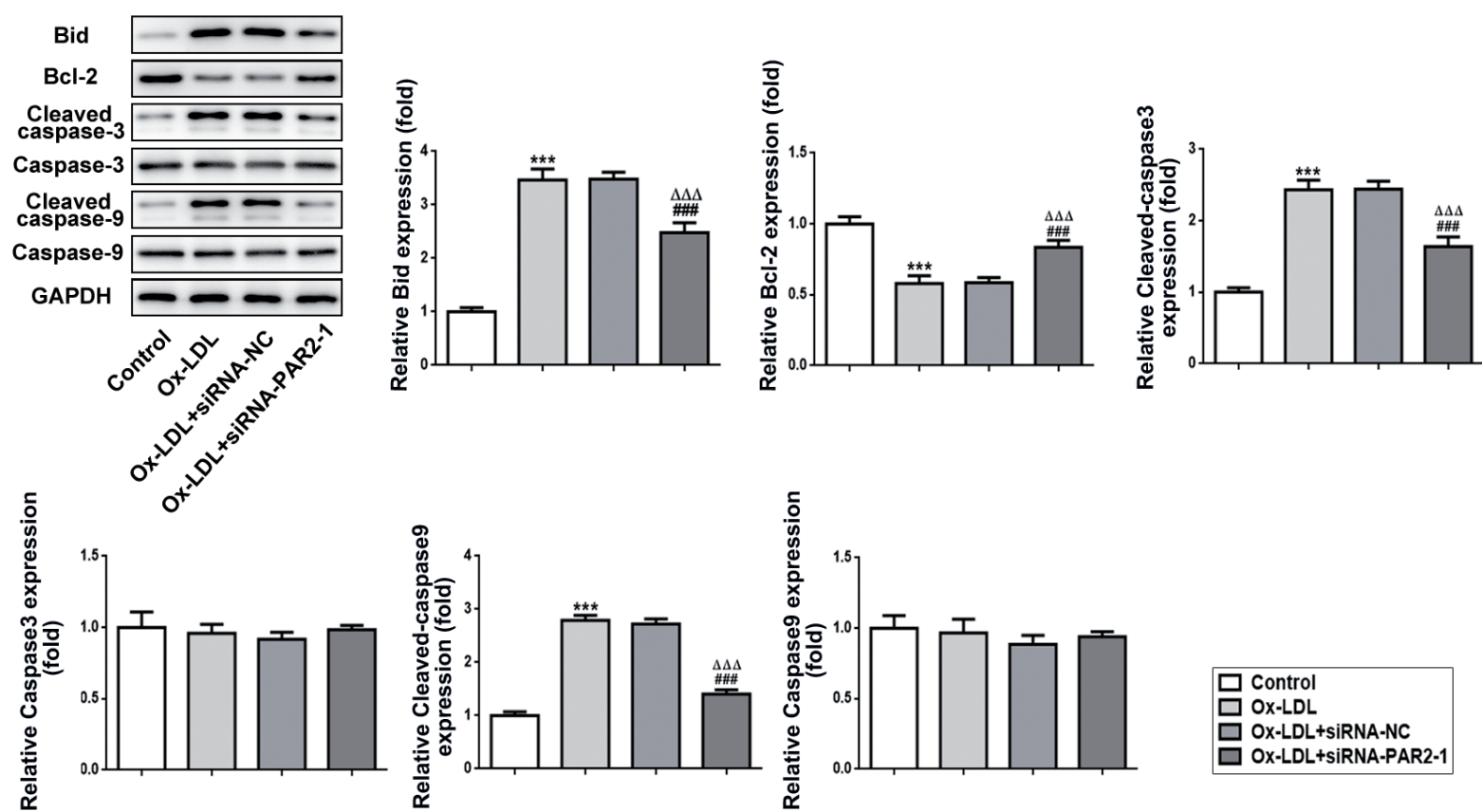

Figure 4. PAR2 expression was involved in ox-LDL-induced apoptosis. A. Flow cytometry was used to evaluate apoptosis. B. The apoptotic proteins were assessed by Western blotting. ${ }^{* *} p<0.001$ vs. Control group; ${ }^{\# \# \#} p<0.001$ vs. ox-LDL group; ${ }^{\Delta \Delta \Delta} p<0.001 v s$. ox-LDL+siRNA-NC group.

Lower levels of PAR2 activated Wnt/ $\beta$-catenin signaling pathway and inhibited DKK1t

As shown in Figure 5, ox-LDL also enhanced the expression of DKK1 in macrophages. DKK1 is an inhibitor for Wnt signaling. Results showed that Wnt3a was prominently annihilated in macrophages treated with ox-LDL. The downstream GSK3 $\beta$ was dramatically enhanced and $\beta$-catenin was reduced. However, PAR2 silence inhibited DKK1 expression and activated $\mathrm{Wnt} / \beta$-catenin signaling.

To investigate whether PAR2 plays roles in macrophages treated with ox-LDL via DKK1/Wnt/GSK3 $\beta / \beta$-catenin signaling, we overexpressed DKK1 in PAR2 silenced macrophages using a pcDNA3.0-DKK1 plasmid (Fig. 6A). Results showed that overexpression of DKK1 promoted lipid accumulation and cholesterol levels in macrophages treated with ox-LDL (Fig. 6B and C). Also, overexpression of DKK1 promoted levels of TNF- $\alpha$, IL-1 $\beta$, IL-6, and MCP-1 in PAR2 silenced macrophages with ox-LDL treatment (Fig. 6D). The inflammasome key points including NLRP3, ASC, and caspase-1 were also increased by overexpression of DKK1 (Fig. 6E). After then, the enhancement of DKK1 promoted apoptosis (Fig. 7A). Pro-apoptotic protein like Bid, caspase-3 and caspase- 9 was activated, yet anti-apoptotic protein Bcl-2 was inhibited (Fig. 7B). These data elucidate that PAR2 participates in ox-LDL induced foam cell formation, inflammation and apoptosis mediated by $\mathrm{Wnt} / \beta$-catenin signaling pathway.

PAR2 overexpression enhanced the inflammation and apoptosis by regulating DKK1/Wnt/ $\beta$-catenin signaling

To further confirm that ox-LDL induced apoptosis and inflammation by regulating PAR2 expression, PAR2 was 

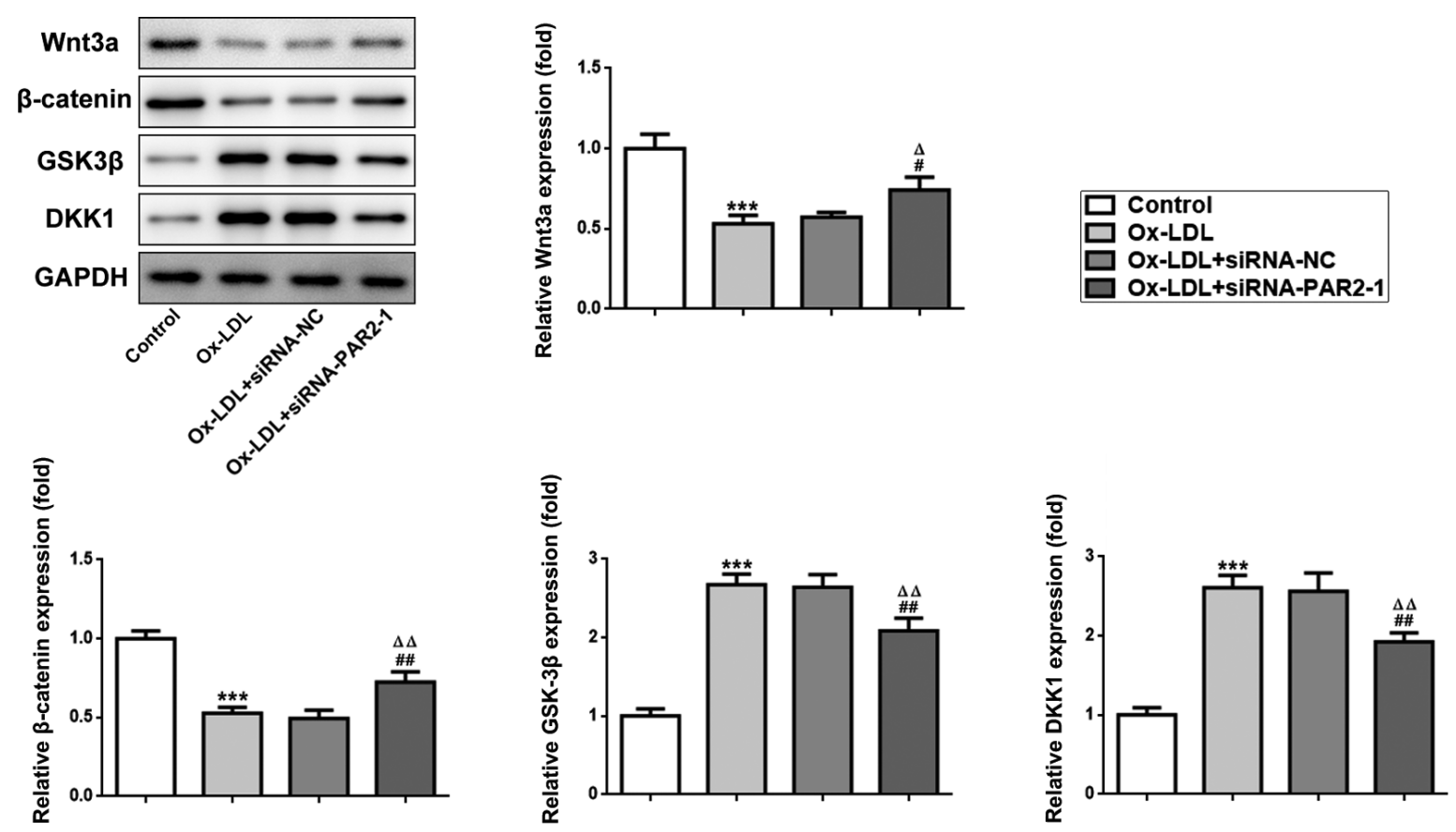

Figure 5. Wnt/ $\beta$-catenin/GSK3 $\beta / D K K 1$ signaling pathway was activated by PAR2. Western blotting and protein bands analysis were performed for the determination of the expression of Wnt/ $\beta$-catenin/GSK3 $\beta / \mathrm{DKK} 1$ signaling. ${ }^{* *} p<0.001$ vs. Control group; ${ }^{\#} p<0.05$, ${ }^{\# \#} p<0.01$ vs. ox-LDL group; ${ }^{\Delta} p<0.05,{ }^{\Delta \Delta} p<0.01$ vs. ox-LDL+siRNA-NC group.

overexpressed in macrophages (Fig. 8A). The overexpression of PAR 2 in macrophages promoted the TNF- $\alpha$, IL- $1 \beta$, IL-6, and MCP-1 production compared to empty plasmid control (NC), which was similar as the influence of oxLDL on these pro-inflammatory factors (Fig. 8B). Also, overexpression of PAR2 robustly enhanced the expression of ASC, caspase-1, and NLRP3 (Fig. 8C). The expression levels of pro-apoptotic protein Bid, cleaved-caspase 3 and cleaved-caspase 9 were increased, whereas the anti-apoptotic protein $\mathrm{Bcl}-2$ was decreased both in ox-LDL group and PAR2 overexpressed cells (Fig. 8D). The higher levels of DKK1 both in ox-LDL and PAR2 than in control or NC indicated that ox-LDL enhanced PAR2 positively regulates DKK1 expression (Fig. 8E). Following that, the decrease of Wnt $3 \mathrm{a}$ and $\beta$-catenin, and the increase of GSK3 $\beta$ in oxLDL group and PAR2 overexpressed group revealed that ox-LDL stimulated PAR2 expression and DKK1/Wnt/ $\beta$ catenin signaling (Fig. $8 \mathrm{E}$ ). These data directly indicated that PAR2 regulates DKK1/Wnt/ $\beta$-catenin signaling to promote inflammation and apoptosis.

\section{Discussion}

Atherosclerosis is initiated by the foam cell formation which will lead to inflammation and apoptosis. Atherosclerosis is a lipid-driven inflammatory disease. Under the progression of atherosclerosis, the monocytes adhere to endothelial cells and migrate into the vulnerable area of the artery, and subsequently differentiate into macrophages to promote uptake of ox-LDL. Conversion of macrophages to foam cells is mainly resulted by the increase of the extra cholesterol and decrease of lipid efflux. Researches and our previous investigation showed that PAR2 levels were enhanced in human coronary atherosclerotic lesions (Napoli et al. 2004). Plaque formation involves endothelial dysfunction cells, smooth muscle cells, leukocytes, foam cells, and extracellular matrix. A current study found that PAR2 expression was upregulated in ox-LDL induced in macrophages. The inhibition of PAR2 reduced the conversion of macrophages to foam cells. The dysfunction of cholesterol metabolism is a key point for atherosclerosis progression. Accumulation of cholesterol in macrophages promoted foam cell formation (Fan et al. 2019). The cholesterol efflux is an important part of the regulation of cholesterol homeostasis to avoid cholesterol accumulation and foam cell formation.

Secretion of MCP-1 recruits macrophages and vascular smooth muscle cells migration to intima (Chae et al. 2012). Lipid deposition by macrophages plays a key role in plaque formation during atherosclerotic progression. ox-LDL uptake produces foam cells to release pro-inflammatory cytokines, including IL-1 $\beta$, TNF- $\alpha$, and IL-6 (Feng et al. 2019). Our investigation also showed the same results. Moreover, 
we found that knock-down of PAR2 reversed the ox-LDL induced inflammation and PAR2 overexpression showed the similar pathological effects as ox-LDL treatment.
Caspase- 3 was activated in neointimal macrophages after arterial injury which related to apoptosis in lipid-rich plaque (Hutter et al. 2004). In the presence of ox-LDL, macrophages
A

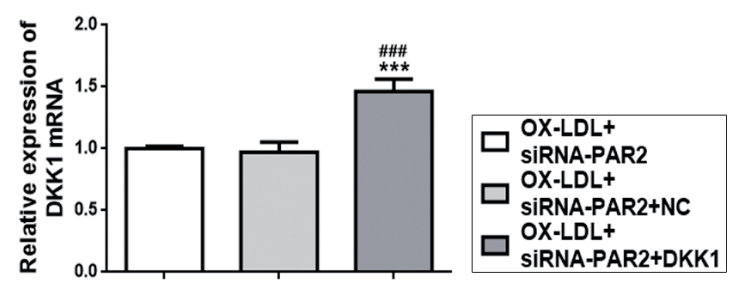

C

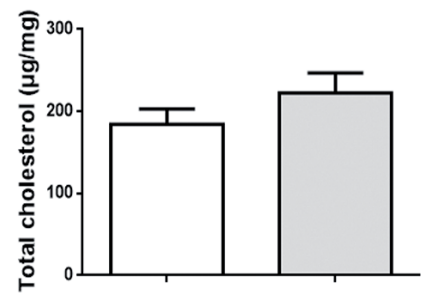

B

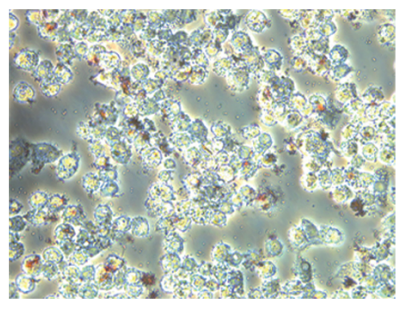

Ox-LDL+
SIRNA-PAR2-1

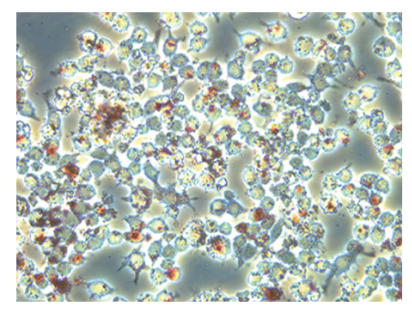

OX-LDL+

SIRNA-PAR2-1+DKK1

D
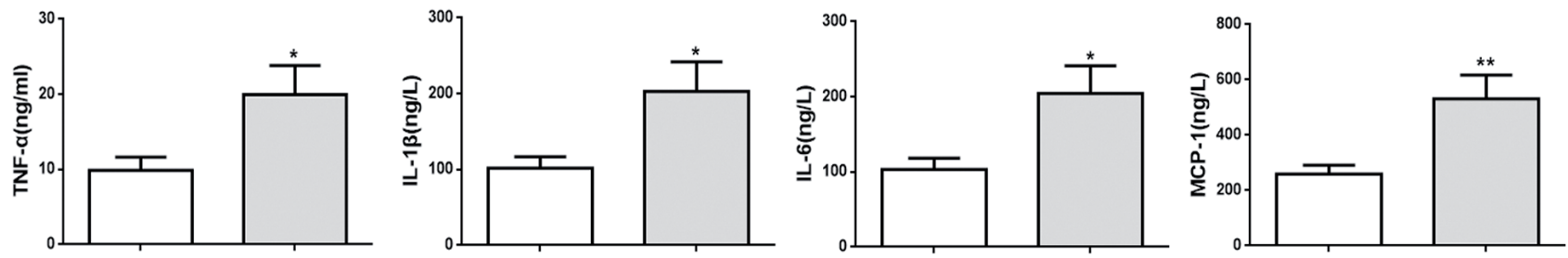

E
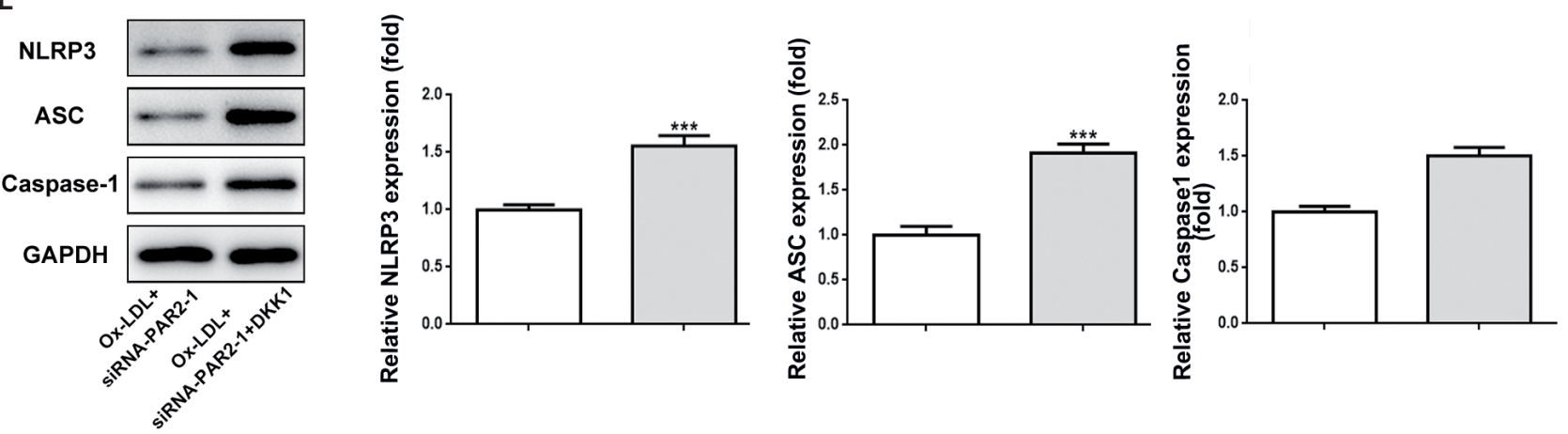

Figure 6. DKK1 overexpression reversed the effects in PAR2 silenced macrophages with ox-LDL treatment. A. Transfected efficacy of DKK1 in THP-1 cells. B. Oil Red O staining was performed to investigate the effect of DKK1 on lipid accumulation (magnification 400×). C. The levels of total cholesterol and free cholesterol in macrophages were detected by the commercial assay kit. D. ELISA detection of TNF- $\alpha$, IL-1 $\beta$, IL-6, and MCP-1 in the supernatant of macrophages. E. The inflammasome expression was detected by Western blotting. ${ }^{*} p<0.05,{ }^{* *} p<0.01,{ }^{* * *} p<0.001$ vs. ox-LDL+siRNA-PAR2 group; ${ }^{\# \# \#} p<0.001 v$ s. ox-LDL+siRNA-PAR2-DKK1 group. 
A

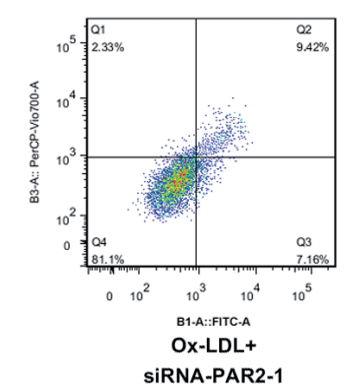

B

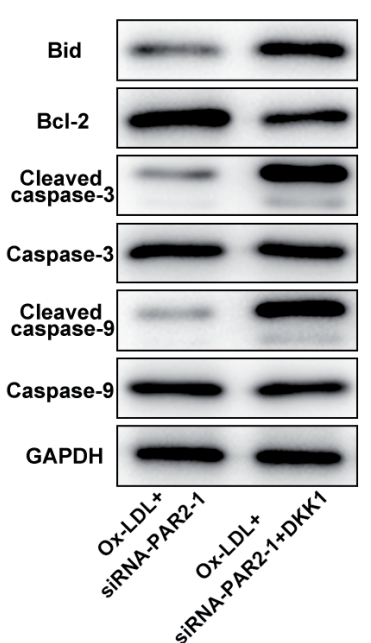

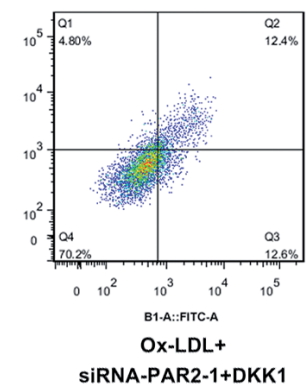

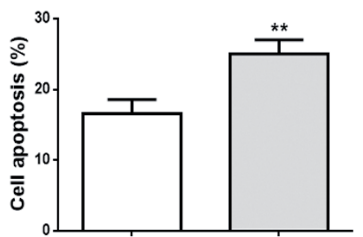

OX-LDL+ SIRNA-PAR2-1

OX-LDL+ siRNA-PAR2-1+DKK1
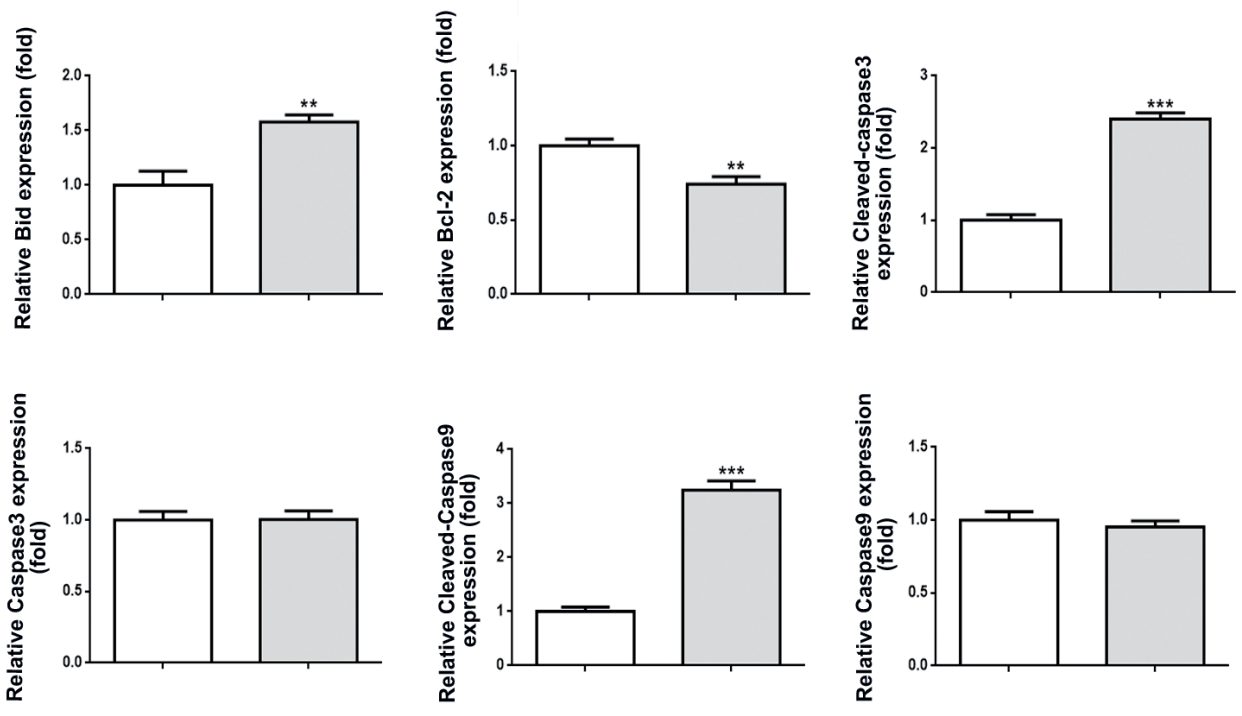

Figure 7. DKK1 overexpression increased apoptosis in PAR2 silenced macrophages with ox-LDL treatment. A. Apoptosis was determined by flow cytometry. B. The apoptotic proteins were estimated by Western blotting. ${ }^{* *} p<0.01,{ }^{* *} p<0.001 v s$. ox-LDL+siRNAPAR2 group.

form to foam cells and further induce macrophage apoptosis which plays role in the formation and accumulation of the lipid core (Hegyi et al. 1996). PAR2 silence dramatically reduced ox-LDL-induced apoptosis and activation of caspase- 3 and caspase- 9 . The Bid is a Bax similar protein, which translocases from the cytosol to mitochondria, leading to apoptosis (Billen et al. 2008), and Bcl-2 inhibits translocation. Inhibition of PAR2 upregulated Bcl-2 expression and downregulated Bid in macrophages treated with ox-LDL. PAR2 overexpression showed the similar biological effects as ox-LDL treatment on apoptosis, suggesting that ox-LDL induced apoptosis by PAR2 upregulation.

DKK1 expression is upregulated in ApoE-/- mice resulting in enlarged and destabilized atherosclerotic lesions (Di et al. 2017). A previous investigation showed that inhibition of DKK1 inhibits the intracellular lipid droplet accumulation compared with control under ox-LDL treatment (Zhang et al. 2015). Also, overexpression of DKK1 in JEG3 cells suppressed the accumulation of lipoid and downregulation of peroxisome proliferator-activated recep- tor $\delta$ (Strakovsky and Pan 2012). Our study showed that silenced PAR2 in macrophages treated with ox-LDL suppressed the expression of DKK1. The increasing lipid droplets accumulation and high levels of cholesterol indicated that overexpression of DKK1 promotes the macrophage conversion to foam cells. It has been proved that Wnt pathway activation participates in macrophage motility and lipid internalization (Borrell-Pages et al. 2011). Suppressing Wnt $/ \beta$-catenin signaling pathway dramatically inhibited the cholesterol efflux in THP-1 macrophage-derived foam cells (Liu et al. 2020). We found that PAR2 overexpression suppressed the expression of DKK1. The DKK1 gene encodes a member of DKK family proteins which bind to the LRP6 co-receptor and inhibits $\beta$-catenin-dependent Wnt signaling. Therefore, PAR2 suppressed DKK1 to be able to activate the subsequent signaling Wnt $/ \beta$-catenin regulating conversion of macrophage to foam cell. Besides, Wnt $/ \beta$-catenin dramatically reduced activity of GSK- $3 \beta$ that is a regulator of NF- $\mathrm{KB}$ regulating inflammation (Schaale et al. 2011). The production of pro-inflammatory factors 


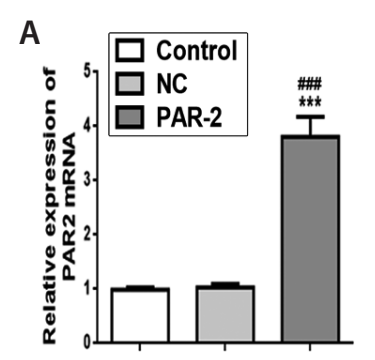

B
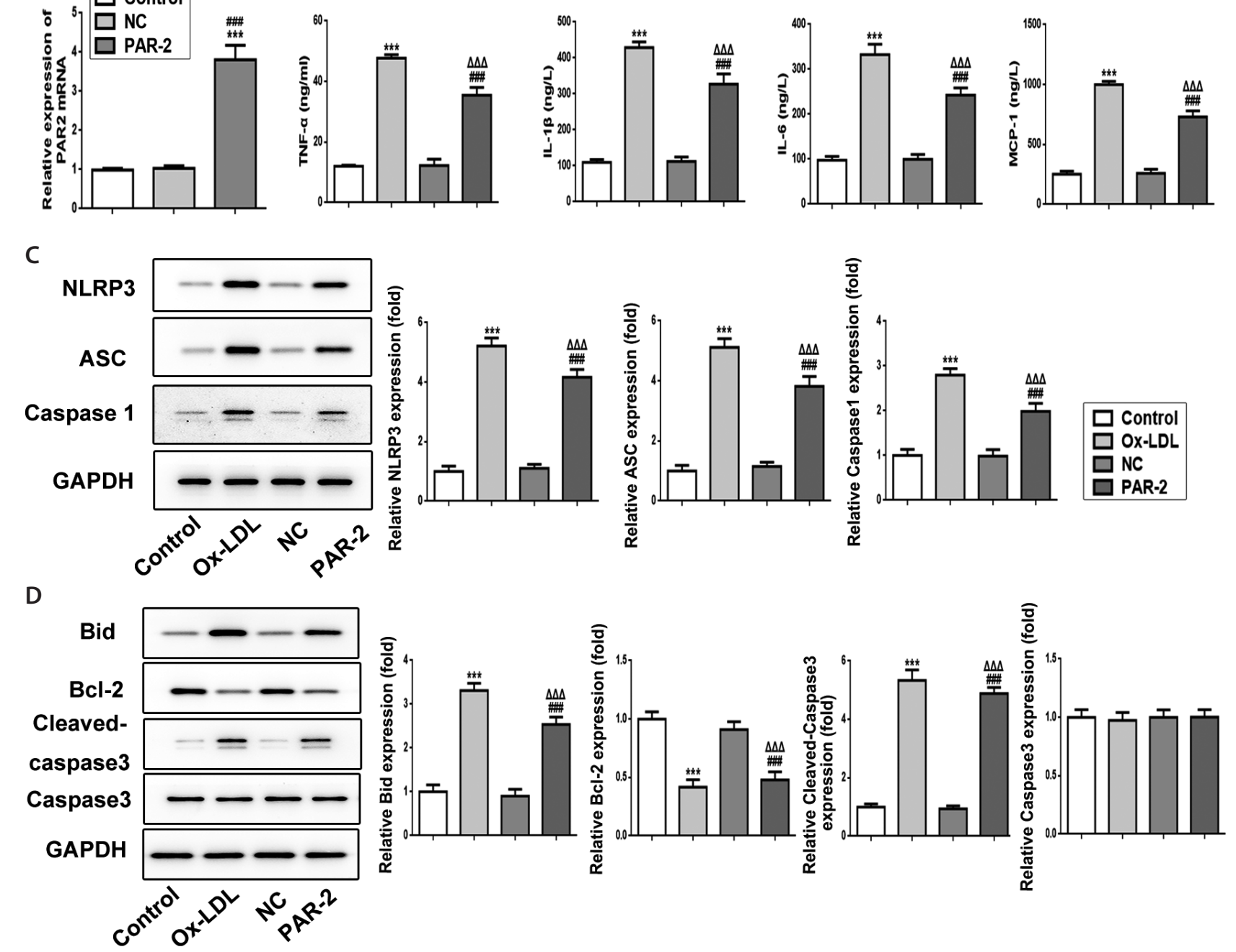

E
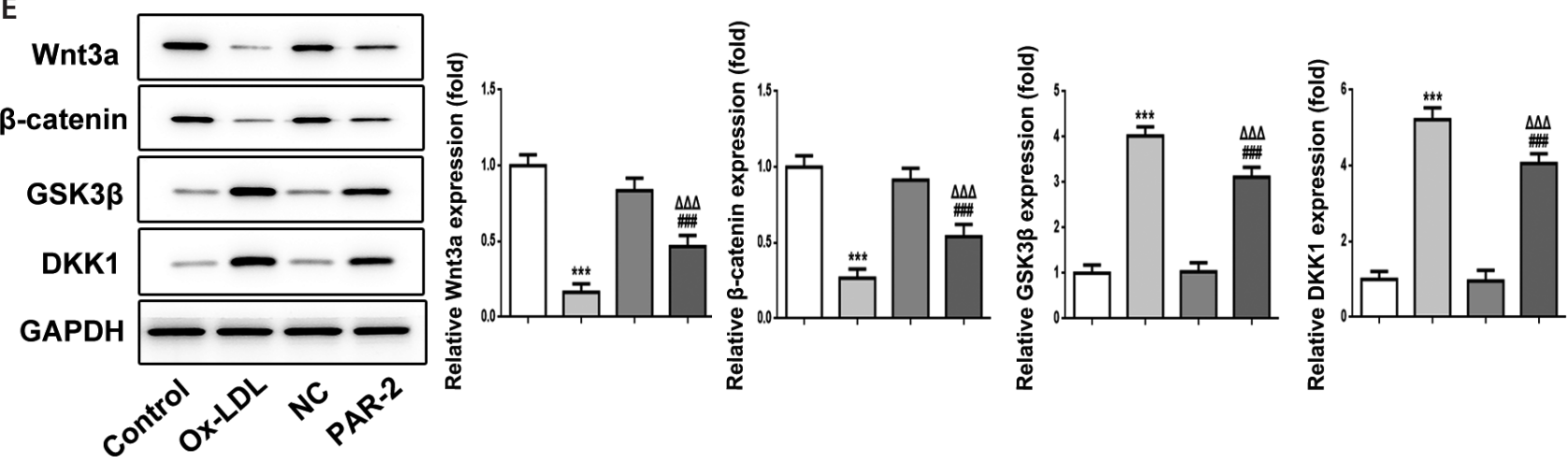

Figure 8. PAR2 overexpression in macrophages showed the similar biological effects as ox-LDL treatment. A. Transfected efficacy of PAR2 in THP-1 cells. ${ }^{* *} p<0.001 v s$. Control group; ${ }^{\# \# \#} p<0.001 v s$. NC group. B. ELISA detection of TNF- $\alpha$, IL-1 $\beta$, IL-6, and MCP-1 in the supernatant of macrophages. C. Western blotting and protein bands analysis were performed for the determination of the expression of inflammasome complex NLRP3/ASC/caspase-1. D. The apoptotic proteins were estimated by western blotting. E. Western blotting and protein bands analysis were performed for the determination of the expression of Wnt/ $\beta$-catenin/GSK3 $\beta / D K K 1$ signaling. ${ }^{* * *} p<0.001$, $\# \#$ \# $0.001 v$ s. Control group; ${ }^{\Delta \Delta \Delta} p<0.001 v s$. NC group. NC, the macrophages transfected with empty pcDNA3.1 plasmid; PAR2, the macrophages transfected with pcDNA3.1-PAR2 plasmid. 
including TNF- $\alpha$, IL- $1 \beta$, and IL- 6 was also enhanced by overexpression of DKK1. Inhibition of PAR-2 also alleviated the expression of DKK1 and GSK- $3 \beta$ activity, however, DKK1 reversed this effect. Therefore, the effects of PAR- 2 in macrophages treated with ox-LDL may mediate by DKK1/ Wnt/ $\beta$-catenin signaling pathway.

In conclusion, our investigation suggests that PAR2 participates in alterations in macrophages stimulated with ox-LDL by suppressing the activity of the Wnt/ $\beta$-catenin signaling pathway. PAR2 affects the formation of foam cell, inflammation, and apoptosis via DKK1/Wnt/ $\beta$-catenin pathways. DKK1 enhances lipid accumulation, inflammation and apoptosis in macrophages stimulated with ox-LDL. Previous investigations have found that PAR2 silencing suppresses atherosclerotic progression in mice. Our study provides a more theoretical basis for the future clinical study of PAR2 silencing therapeutic strategy.

Conflict of interests. The authors declare that there are no conflicts of interest.

\section{References}

Antoniak S, Mackman N (2014): Multiple roles of the coagulation protease cascade during virus infection. Blood 123, 2605-2613

https://doi.org/10.1182/blood-2013-09-526277

Billen LP, Shamas-Din A, Andrews DW (2008): Bid: a Bax-like BH3 protein. Oncogene 27 (Suppl. 1), S93-104 https://doi.org/10.1038/onc.2009.47

Borrell-Pages M, Romero JC, Juan-Babot O, Badimon L (2011): Wnt pathway activation, cell migration, and lipid uptake is regulated by low-density lipoprotein receptor-related protein 5 in human macrophages. Eur. Heart J. 32, 2841-2850 https://doi.org/10.1093/eurheartj/ehr062

Cai X, Bao L, Dai X, Ding Y, Zhang Z, Li Y (2015): Quercetin protects RAW264.7 macrophages from glucosamine-induced apoptosis and lipid accumulation via the endoplasmic reticulum stress pathway. Mol. Med. Rep. 12, 7545-7553 https://doi.org/10.3892/mmr.2015.4340

Chae IG, Yu MH, Im NK, Jung YT, Lee J, Chun KS, Lee IS (2012): Effect of Rosemarinus officinalis L. on MMP-9, MCP-1 levels, and cell migration in RAW 264.7 and smooth muscle cells. J. Med. Food 15, 879-886 https://doi.org/10.1089/jmf.2012.2162

Chen L, Gao B, Zhang Y, Lu H, Li X, Pan L, Yin L, Zhi X (2019): PAR2 promotes M1 macrophage polarization and inflammation via FOXO1 pathway. J. Cell. Biochem. 120, 9799-9809 https://doi.org/10.1002/jcb.28260

Di M, Wang L, Li M, Zhang Y, Liu X, Zeng R, Wang H, Chen Y, Chen W, Zhang Y, Zhang M (2017): Dickkopf1 destabilizes atherosclerotic plaques and promotes plaque formation by inducing apoptosis of endothelial cells through activation of ER stress. Cell Death Dis. 8, e2917 https://doi.org/10.1038/cddis.2017.277
Fan J, Liu L, Liu Q, Cui Y, Yao B, Zhang M, Gao Y, Fu Y, Dai H, Pan J, Qiu Y, Liu CH, He F, Wang Y, Zhang L (2019): CKIP1 limits foam cell formation and inhibits atherosclerosis by promoting degradation of Oct-1 by REGgamma. Nat. Commun. 10, 425 https://doi.org/10.1038/s41467-018-07895-3

Feng C, Chen Q, Fan M, Guo J, Liu Y, Ji T, Zhu J, Zhao X (2019): Platelet-derived microparticles promote phagocytosis of oxidized low-density lipoprotein by macrophages, potentially enhancing foam cell formation. Ann. Transl. Med. 7, 477 https://doi.org/10.21037/atm.2019.08.06

Hamilton JR, Cornelissen I, Mountford JK, Coughlin SR (2009): Atherosclerosis proceeds independently of thrombin-induced platelet activation in ApoE-/-mice. Atherosclerosis 205, 427432 https://doi.org/10.1016/j.atherosclerosis.2009.01.018

Hara T, Phuong PT, Fukuda D, Yamaguchi K, Murata C, Nishimoto S, Yagi S, Kusunose K, Yamada H, Soeki T, et al. (2018): Protease-activated receptor-2 plays a critical role in vascular inflammation and atherosclerosis in apolipoprotein E-deficient mice. Circulation 138, 1706-1719 https://doi.org/10.1161/CIRCULATIONAHA.118.033544

Hegyi L, Skepper JN, Cary NR, Mitchinson MJ (1996): Foam cell apoptosis and the development of the lipid core of human atherosclerosis. J. Pathol. 180, 423-429

https://doi.org/10.1002/(SICI)1096-9896(199612)180:4<423::AID-PATH677>3.0.CO;2-1

Hutter R, Valdiviezo C, Sauter BV, Savontaus M, Chereshnev I, Carrick FE, Bauriedel G, Luderitz B, Fallon JT, Fuster V, Badimon JJ (2004): Caspase-3 and tissue factor expression in lipid-rich plaque macrophages: evidence for apoptosis as link between inflammation and atherothrombosis. Circulation 109, 2001-2008 https://doi.org/10.1161/01.CIR.0000125526.91945.AE

Jones SM, Mann A, Conrad K, Saum K, Hall DE, McKinney LM, Robbins N, Thompson J, Peairs AD, Camerer E, et al. (2018): PAR2 (protease-activated receptor 2) deficiency attenuates atherosclerosis in mice. Arterioscler. Thromb. Vasc. Biol. 38, 1271-1282 https://doi.org/10.1161/ATVBAHA.117.310082

Liu W, Chen X, Wu M, Li L, Liu J, Shi J, Hong T (2020): Recombinant Klotho protein enhances cholesterol efflux of THP-1 macrophage-derived foam cells via suppressing Wnt/betacatenin signaling pathway. BMC Cardiovasc. Disord. 20, 120 https://doi.org/10.1186/s12872-020-01400-9

Napoli C, de Nigris F, Wallace JL, Hollenberg MD, Tajana G, De Rosa G, Sica V, Cirino G (2004): Evidence that protease activated receptor 2 expression is enhanced in human coronary atherosclerotic lesions. J. Clin. Pathol. 57, 513-516 https://doi.org/10.1136/jcp.2003.015156

Popovic M, Paskas S, Zivkovic M, Burysek L, Laumonnier Y (2010): Human cytomegalovirus increases HUVEC sensitivity to thrombin and modulates expression of thrombin receptors. J. Thromb. Thrombolysis 30, 164-171 https://doi.org/10.1007/s11239-010-0447-7

Raghavan S, Singh NK, Mani AM, Rao GN (2018): Proteaseactivated receptor 1 inhibits cholesterol efflux and promotes atherogenesis via cullin 3-mediated degradation of the ABCA1 transporter. J. Biol. Chem. 293, 10574-10589 https://doi.org/10.1074/jbc.RA118.003491 
Rana R, Shearer AM, Fletcher EK, Nguyen N, Guha S, Cox DH, Abdelmalek M, Wang Y, Baleja JD, Covic L, Kuliopulos A (2019): PAR2 controls cholesterol homeostasis and lipid metabolism in nonalcoholic fatty liver disease. Mol. Metab. 29, 99-113 https://doi.org/10.1016/j.molmet.2019.08.019

Schaale K, Neumann J, Schneider D, Ehlers S, Reiling N (2011): Wnt signaling in macrophages: augmenting and inhibiting mycobacteria-induced inflammatory responses. Eur. J. Cell. Biol. 90, 553-559 https://doi.org/10.1016/j.ejcb.2010.11.004

Steinberg D (1997): Low density lipoprotein oxidation and its pathobiological significance. J. Biol. Chem. 272, 20963-20966 https://doi.org/10.1074/jbc.272.34.20963

Strakovsky RS, Pan YX (2012): A decrease in DKK1, a WNT inhibitor, contributes to placental lipid accumulation in an obesity-prone rat model. Biol. Reprod. 86, 81 https://doi.org/10.1095/biolreprod.111.094482

Tabas I, Williams KJ, Boren J (2007): Subendothelial lipoprotein retention as the initiating process in atherosclerosis: update and therapeutic implications. Circulation 116, 1832-1844 https://doi.org/10.1161/CIRCULATIONAHA.106.676890

Wang D, Wang W, Lin W, Yang W, Zhang P, Chen M, Ding D, Liu C, Zheng J, Ling W (2018): Apoptotic cell induction of miR$10 \mathrm{~b}$ in macrophages contributes to advanced atherosclerosis progression in ApoE-/- mice. Cardiovasc. Res. 114, 1794-1805 https://doi.org/10.1093/cvr/cvy132

Yeong P, Ning Y, Xu Y, Li X, Yin L (2010): Tryptase promotes human monocyte-derived macrophage foam cell formation by suppressing LXRalpha activation. Biochim. Biophys. Acta 1801, 567-576 https://doi.org/10.1016/j.bbalip.2010.01.011

Zahid MDK, Rogowski M, Ponce C, Choudhury M, MoustaidMoussa N, Rahman SM (2019): CCAAT/enhancer-binding protein beta (C/EBPbeta) knockdown reduces inflammation, ER stress, and apoptosis, and promotes autophagy in oxLDL-treated RAW264.7 macrophage cells. Mol. Cell. Biochem. 463, 211-223 https://doi.org/10.1007/s11010-019-03642-4

Zhang Y, Ge C, Wang L, Liu X, Chen Y, Li M, Zhang M (2015): Induction of DKK1 by ox-LDL negatively regulates intracellular lipid accumulation in macrophages. FEBS Lett. 589, 52-58

https://doi.org/10.1016/j.febslet.2014.11.023

Zhou J, Lhotak S, Hilditch BA, Austin RC (2005): Activation of the unfolded protein response occurs at all stages of atherosclerotic lesion development in apolipoprotein E-deficient mice. Circulation 111, 1814-1821 https://doi.org/10.1161/01.CIR.0000160864.31351.C1

Received: November 27, 2019

Final version accepted: April 8, 2020 